Eduvest - Journal of Universal Studies

Volume 1 Number 11, November 2021

p- ISSN 2775-3735 e-ISSN 2775-3727

\title{
RISK FACTORS FOR HAND DERMATITIS IN HOSPITAL NURSES IN SUKOHARJO
}

Budi Rahmawati and Ratih Pramuningtyas

Muhammadiyah Surakarta University, Indonesia

E-mail: dr.rahmadexa@gmail.com, Rp110@ums.ac.id

\begin{tabular}{|c|c|}
\hline ARTICLE INFO & ABSTRACT \\
\hline $\begin{array}{l}\text { Received: } \\
\text { October, 26 } \\
2021 \\
\text { Revised: } \\
\text { November, } 16^{\text {th }} \\
2021 \\
\text { Approved: } \\
\text { November, } 18^{\text {th }} \\
2021\end{array}$ & $\begin{array}{l}\text { Hands are organs that play a role in communication, } \\
\text { because in some jobs shaking hands is crucial. People who } \\
\text { are at risk of getting this disease include health workers } \\
\text { and it will have an impact in the future. The purpose of } \\
\text { this study was to determine the risk factors for hand } \\
\text { dermatitis in hospital nurses in Sukoharjo. This type of } \\
\text { research is descriptive analytic research with cross } \\
\text { sectional design. Cross sectional is a non-experimental } \\
\text { research to study the dynamics of the correlation } \\
\text { between risk factors and effects, by approach, } \\
\text { observation or data collection all at once (point time } \\
\text { approach). The research was conducted at dr. New Oen } \\
\text { Solo. The research was conducted in November-February } \\
2020 \text {. Based on the analysis and discussion, it can be } \\
\text { concluded that risk factors, wet work, atopic history, age, } \\
\text { gender, years of service are not related to the incidence } \\
\text { of hand dermatitis in hospital nurses in Sukoharjo. }\end{array}$ \\
\hline KEYWORDS & Risk Factor, Hand Dermatitis, Nurses \\
\hline (i) (강 & $\begin{array}{l}\text { This work is licensed under a Creative Comr } \\
\text { Attribution-ShareAlike } 4.0 \text { International }\end{array}$ \\
\hline
\end{tabular}

\section{INTRODUCTION}

The skin is the first line of defense when the body comes into contact with various types of chemicals. Hand dermatitis or hand eczema is a chronic disease and is caused by many factors (Agarwal, Besarwal, Gupta, Agarwal, \& Napalia, 2014). This

Budi Rahmawati and Ratih Pramuningtyas. (2021). Risk Factors for Hand Dermatitis in Hospital Nurses in Sukoharjo. Journal Eduvest.

How to cite:

E-ISSN:

Published by: $\quad$ https://greenpublisher.id/ 
disease is usually associated with occupational diseases or daily activities in the household. Hand dermatitis can occur due to direct exposure to chemicals that are irritants to the hands, such as soap, detergent, perfume, iron, rubber and repeated exposure such as irritant contact dermatitis or allergic contact dermatitis. However, in some cases, the specific cause that causes hand dermatitis is not specific because in some cases these complaints can be caused by a combination of complaints originating from atopic dermatitis, irritant contact dermatitis, or allergic contact dermatitis (Tan, Rasool, \& Johnston, 2014).

The prevalence of hand dermatitis is difficult to know because not everyone who feels this complaint goes to treatment services (Santer et al., 2012). However 2-10\% of the population is known to suffer from this disease during their lifetime. As many as 20$30 \%$ various types of dermatitis attack the hands, and it can be concluded that this disease is a common occupational disease. Women are more often affected by this disease than men (2:1) due to increased exposure to wet work and household chemicals.

The pathogenesis of hand dermatitis varies depending on the underlying disease. If caused by irritant contact dermatitis, the reaction that occurs is due to direct trauma caused by irritant substances that cause cell damage at a certain time and concentration of certain substances but the immunological process does not occur. Because irritants cause damage or remove the protective layer in the upper epidermis. Usually irritants cause protein denaturation, fat loss, and evaporation of water on the skin.

Seizures of hand dermatitis can be based on allergic contact dermatitis which is a type IV hypersensitivity reaction, caused by an immune reaction mediated by $\mathrm{T}$ cells (Rive, Bourke, \& Phillips, 2013). The inflammatory reaction occurs at the site of contact with the allergen which is characterized by polymorphic forms such as redness, papules, vesicles and followed by with dry skin (Ale \& Maibach, 2014). Itching is the main complaint complained by the patient. Hand dermatitis can also occur in people whose family suffers from atopic dermatitis, asthma and hay fever (Thomsen, 2015).

The appearance of hand dermatitis is diverse, such as hyperkeratotic, nummular, resembling atopic dermatitis, housewives dermatitis, finger tip eczema, chronic acral dermatitis (Sharmila Rao, 2018). The diagnosis of hand dermatitis was made through the patient's general status, progression and remission of dermatitis, occupational history, history of substance exposure, family history, and clinical examination. Examinations that can be performed include patch tests, eosinophil counts, serum IgE levels, skin prick tests, skin biopsies (Salvador et al., 2020).

Hand dermatitis affects one of the important organs, namely the hands and is the most common occupational skin disease. Hands are organs that play a role in communication, because in some jobs shaking hands is crucial. People who are at risk of getting this disease include health workers and it will have an impact in the future. The purpose of this study was to determine the risk factors for hand dermatitis in hospital nurses in Sukoharjo.

\section{RESEARCH METHOD}

This type of research is descriptive analytic research with cross sectional design. Cross sectional is a non-experimental research to study the dynamics of the correlation between risk factors and effects, by approach, observation or data collection all at once (point time approach). The research was conducted at dr. New Oen Solo. The research was conducted in November-February 2020.

The sample in this study was determined using a non-probability sampling technique with a purposive sampling approach where the sampling used was determined based on the decision of the researcher which in his opinion seemed representative of the 
population. The minimum total number of samples in this study was 30 . Data was collected using a questionnaire method using previously validated questionnaires. The questionnaire contains questions that must be answered by the respondent and a checklist sheet of observations that will be filled out by the researcher. The questionnaire in this study included questions about the length of contact, exposure to formic acid, age, gender and history of previous skin diseases.

The data were analyzed statistically based on the variables assessed using a computerized system, namely univariate and bivariate analysis. Univariate analysis was performed to see the frequency distribution. The data is presented in the form of a frequency distribution table. Bivariate analysis was performed using chi-square using the SPSS tool to determine the significant difference due to the relationship between the two research variables. If it does not meet the chi-square requirements, other tests will be used, such as fisher's exact. Finally, multivariate analysis was carried out, if more than 1 variable that met the $\mathrm{P}$ requirements, the logistic regression method would be used. The processed data are presented in the form of distribution tables with explanations arranged in narrative form and grouped according to the research objectives.

\section{RESULT AND DISCUSSION}

\section{A. Characteristics of Respondents}

The research respondents were nurses who met the inclusion criteria and did not have the exclusion criteria. In this study, 40 respondents were obtained, then the research data were collected and analyzed. The following is a description of the characteristics of the respondents in this study.

Table 1 Frequency Distribution of Respondents by Age and Gender

\begin{tabular}{lll}
\hline & $\mathbf{F}$ & $\mathbf{\%}$ \\
\hline Age & & \\
\hline$<30$ year & 4 & 10 \\
30-40 year & 21 & 52,5 \\
40-50 year & 15 & 37,5 \\
$>50$ year & 0 & 0 \\
\hline Total & 40 & 100 \\
\hline Gender & & \\
\hline Male & 5 & 12,5 \\
Female & 35 & 87,5 \\
\hline Total & 40 & 100 \\
\hline
\end{tabular}

Table 1 shows that the characteristics of the respondents based on age are mostly the age group of 30-40 years $(52.5 \%)$. Then, based on gender characteristics, data obtained from male respondents as many as 5 people $(12.5 \%)$ and female respondents as many as 35 people $(87.5 \%)$. 


\section{B. Univariate Analysis}

a) Length of Work

The frequency distribution of respondents' working hours can be seen in table 2 .

Table 2 Frequency Distribution of Respondents' Length of Work

\begin{tabular}{lll}
\hline Length of working & F & \% \\
\hline$<5$ hour & 0 & 0 \\
$5-10$ hour & 8 & 20 \\
$>10$ hour & 32 & 80 \\
\hline Total & 40 & 100 \\
\hline
\end{tabular}

Based on table 2, data shows that from 40 research respondents, 8 people (20\%) worked for 5-10 hours a day and 32 people (80\%) worked for more than 10 hours a day.

b) Hand Dermatitis

The distribution of the frequency of respondents experiencing hand dermatitis can be seen in table 3 below.

Table 3 Distribution of the frequency of respondents experiencing hand dermatitis

\begin{tabular}{lll}
\hline Hand Dermatitis & F & \% \\
\hline Positive & 15 & 37,5 \\
Negative & 25 & 62,5 \\
\hline Total & 40 & 100 \\
\hline
\end{tabular}

Table 3 above shows that of the 40 respondents who experienced hand dermatitis from this study, 15 people (37.5\%). The rest, 25 people (62.5\%) did not experience hand dermatitis.

c) History of Atopy

The frequency distribution of respondents who have a history of atopy can be seen in table 4 below.

Table 4. Frequency distribution of respondents who have a history of atopy

\begin{tabular}{lll}
\hline Atopi History & F & \% \\
\hline Positive & 37 & 92.5 \\
Negative & 3 & 7.5 \\
\hline Total & 40 & 100 \\
\hline
\end{tabular}

Table 4 above shows that of the 40 respondents who had a history of atopy from this study, 37 people $(92.5 \%)$. The rest, 3 people $(7.5 \%)$ had no history of atopy.

d) Wet Work

The frequency distribution of respondents who do wet work can be seen in table 5 below:

Table 5 Distribution of the frequency of respondents doing wet work

\begin{tabular}{lll}
\hline Wet Work & F & \% \\
\hline Positive & 34 & 85 \\
Negative & 6 & 15 \\
\hline Total & 40 & 100 \\
\hline
\end{tabular}


Table 5 above shows that of the 40 respondents in this study, 34 people (85\%) did wet work, while $6(15 \%)$ did not do wet work.

\section{Bivariate Analysis}

To find out the risk factors for hand dermatitis in nurses at Sukoharjo Hospital, a chi square statistical test was carried out but it did not meet the requirements. Therefore, the Fisher exact test was carried out and the following results were obtained as in table 6 .

Table 6 Risk factors for hand dermatitis in hospital nurses in Sukoharjo

\section{Hand Dermatitis}

\begin{tabular}{|c|c|c|c|c|c|c|c|}
\hline \multirow{2}{*}{ Risk Factor } & \multicolumn{2}{|c|}{ Positive } & \multicolumn{2}{|c|}{ Negative } & \multicolumn{2}{|c|}{ Total } & \multirow[t]{2}{*}{$p$ value } \\
\hline & & $\%$ & & & & $\%$ & \\
\hline \multicolumn{8}{|l|}{ Age } \\
\hline$<30$ & 2 & $5 \%$ & 2 & $5 \%$ & 4 & $10 \%$ & \\
\hline $30-40$ & 5 & $12.5 \%$ & 16 & $40 \%$ & 21 & $52.5 \%$ & 0.16 \\
\hline $40-50$ & 8 & $20 \%$ & 7 & $\begin{array}{l}17.5 \\
\%\end{array}$ & 15 & $37.5 \%$ & \\
\hline Total & 15 & $37.5 \%$ & 25 & $\begin{array}{l}62.5 \\
\%\end{array}$ & 40 & $100 \%$ & \\
\hline \multicolumn{8}{|l|}{ Gender } \\
\hline Male & 1 & $2.5 \%$ & 4 & $10 \%$ & 5 & $12.5 \%$ & 0.63 \\
\hline Female & 14 & $35 \%$ & 21 & $\begin{array}{l}52.5 \\
\%\end{array}$ & 35 & $87.5 \%$ & \\
\hline Total & 15 & $37.5 \%$ & 25 & $\begin{array}{l}62.5 \\
\%\end{array}$ & 40 & $100 \%$ & \\
\hline \multicolumn{8}{|l|}{$\begin{array}{l}\text { Length } \\
\text { working }\end{array}$} \\
\hline 5-10 hour & 2 & $5 \%$ & 6 & $15 \%$ & 8 & $20 \%$ & \\
\hline$>10$ hour & 13 & $32.5 \%$ & 19 & 47.5 & 32 & $80 \%$ & 0.35 \\
\hline Total & 15 & $37.5 \%$ & 25 & $\begin{array}{l}62.5 \\
\%\end{array}$ & 40 & $100 \%$ & \\
\hline \multicolumn{8}{|l|}{ Atopi History } \\
\hline Positive & 13 & $32.5 \%$ & 24 & $60 \%$ & 37 & $92.5 \%$ & \\
\hline Negative & 2 & $5 \%$ & 1 & $\begin{array}{l}2.5 \\
\%\end{array}$ & 3 & $7.5 \%$ & 0.31 \\
\hline Total & 15 & $37.5 \%$ & 25 & $\begin{array}{l}62.5 \\
\%\end{array}$ & 40 & $100 \%$ & \\
\hline \multicolumn{8}{|l|}{ Wet work } \\
\hline Positive & 14 & $35 \%$ & 20 & $50 \%$ & 34 & $85 \%$ & \\
\hline Negative & 1 & $2.5 \%$ & 5 & $\begin{array}{l}12.5 \\
\%\end{array}$ & 6 & $15 \%$ & 0.25 \\
\hline
\end{tabular}




\begin{tabular}{lllllll}
\hline Total & 15 & $37.5 \%$ & 25 & $\%$ & 40 & $100 \%$ \\
\hline
\end{tabular}

From the data contained in table 5.6, it was found that 2 respondents who experienced hand dermatitis aged $<30$ years $(5 \%), 30-40$ years old were $5(12.5 \%), 8$ people 40-50 years old (20\%). Most of the respondents were 14 women (35\%) and 1 man (2.5\%). Respondents with 5-10 hours working duration were 2 people (5\%), working hours $>10$ hours were 13 people (32.5\%). In respondents with a history of atopy, 13 people $(32.5 \%)$ experienced hand dermatitis, while in respondents who did not have a history of atopy, 2 people (5\%) experienced hand dermatitis. Hand dermatitis also occurred in nurses who did wet work as many as 14 people $(35 \%)$ while nurses who did not do wet work occurred in 1 respondent $(2.5 \%)$.

Based on the data in table 5.6, the $\mathrm{p}$ value obtained from the statistical tests carried out is $0.35(>0.05)$ for the length of work, $0.31(>0.05)$ for respondents with a history of atopy and 0.25 ( $>0$, for respondents who do wet work). 05 ) so that it can be concluded that the length of work, history of atopy and wet work are not significant as risk factors for the occurrence of hand dermatitis in this study.

\section{Discussion}

\section{a) Gender and age with hand dermatitis}

In this study, there were more cases of hand dermatitis in women as many as 14 people compared to 1 person in men. Similar results were obtained in a study conducted by Adilah Afifah, the female gender has a risk of experiencing contact dermatitis on the hands 1.8 times compared to the male sex. Of the 28 cases of contact dermatitis, $85.7 \%$ were found to be female, while the remaining $14.3 \%$ were male. female $(46.7 \%)$.

From an experimental and epidemiological study, women do not have skin that is more sensitive to irritation than men's skin. The difference in the incidence of hand dermatitis between men and women is not the result of differences in skin barrier function, but rather due to differences in external exposure (Dąbrowska et al., 2018).

The most positive age for experiencing hand dermatitis in this study was the age of 40-50 years. There is a great deal of age-related variation in the prevalence of hand dermatitis in other studies. Dermatitis can be experienced by all age groups. An older person has dry, thin skin that is intolerant of soaps and solvents. 4 Dryness of the skin can make it easier for chemicals to infect the skin, making the skin more susceptible to dermatitis. In the elderly, there is usually a failure in the treatment of contact dermatitis, resulting in chronic dermatitis. It can be said that contact dermatitis will be more easily attacked in workers with an older age. However, from several research results, workers with a younger age are actually more affected by contact dermatitis, this is supported by the results of research conducted by Lestari and Utomo that as many as $26(60.5 \%)$ of 43 workers aged $<30$ years exposed to contact dermatitis, while among workers aged $>30$ years only about 13 people $(35.1 \%)$ were affected by contact dermatitis. 5

In one study, age risk factors were shown to be not significantly associated with the incidence of hand dermatitis (Mortz, Bindslev - Jensen, \& Andersen, 2014). The average age of subjects with hand dermatitis and without hand dermatitis was almost the same so that the statistical test results of age did not significantly affect the incidence of hand dermatitis. Most of the research subjects with hand dermatitis were over 40 years old. Taylor et al mentioned that after the age of 30 years, the production of important hormones such as testosterone, growth hormone, and estrogen begins to decrease, while these hormones affect skin health. So that along with increasing age, the decline in these 
hormones affects the health of the skin.2 This is in accordance with the results obtained in this study (Cristóbal et al., 2019). The statistical test of this study found a non-significant relationship between age and gender, this is because dermatitis can occur at all ages and genders, meaning that age and gender are not the main risk factors in the occurrence of hand dermatitis.

b) Length of work with hand dermatitis

In this study, it was found that the length of work did not have a significant relationship with the incidence of hand dermatitis. Research conducted by Sholehah in 2017 found the same findings where there was no significant relationship between length of work and dermatitis. 6 Length of work was related to length of contact with irritants or allergens. The longer the contact with irritants or allergens, inflammation or skin irritation can occur, causing the outer layer of skin cells to experience deeper damage.

Pen statistic test in this study did not find a significant relationship between length of work and hand dermatitis, this could be because individual skin has different sensitivities, and the variable length of work also has other factors such as how many times he or she is exposed in a day and contact with $>1$ type of chemical. .7 Nurses also tend to move or roll rooms so that they get different types of exposure.

c) History of atopy with hand dermatitis

In this study, there was no significant relationship between history of atopy and hand dermatitis ( $p>0.05)$. Individuals with atopic have decreased hydration in the stratum corneum and low content of amino acids in the skin, so it will be easier for substances to enter, both irritants and allergens. A non-significant relationship in this study could be due to a history of atopy that can increase a person's susceptibility to the incidence of dermatitis but this is also influenced by other factors such as the amount of exposure and duration of exposure and the type of exposure that causes dermatitis.

In contrast to the results obtained by Thyssen (2010) which showed that atopic history was significantly associated with the incidence of hand dermatitis. Many studies in the general population have reported that atopic history is the most important risk factor for hand dermatitis. 9 Atopic conditions increase the susceptibility of the dermis to irritants and inhibit the healing process. Intact stratum corneum, a protective barrier layer of compacted keratinized epidermal cells, has an important role to prevent the occurrence of DKI and DKA.8

Tanaka et al (1998) reported that atopic individuals had decreased hydration in the stratum corneum and low levels of amino acids in the skin, making it easier for substances to enter, both irritants and allergens. In a prospective cohort study conducted by Diepgen et al. showed that atopic skin diathesis increased the likelihood of developing hand dermatitis with an odds ratio of 2:1. Despite atopic being a major risk factor for hand dermatitis, those with atopic eczema accounted for only $17 \%$ of nurses with hand dermatitis. Reducing the frequency of hand washing is the most effective strategy to reduce the occurrence of hand dermatitis among nurses.

d) Wet Work with hand dermatitis

Wet work is defined as an activity in which workers must immerse hands in liquid for $>2$ hours per shift, or wear waterproof (occlusive) gloves for an appropriate amount of time, or wash hands $>20$ times per shift.14 The analysis in this study found there is no significant relationship between wet work and hand dermatitis $p=>0.05$. Wet work has a significant relationship with the incidence of DT. Wet work in this case is related to water and detergent. Work that requires frequent contact with water causes maceration and dissolution of stratum corneum lipids

Over-hydration of the stratum corneum increases the penetration of foreign material and contributes to the occurrence of irritant contact dermatitis and allergic 
contact dermatitis. In addition, increased frequency of hand washing is an important risk factor for hand dermatitis.15 Denaturation of stratum corneum proteins, changes in intercellular lipids (lipid depletion or reorganization), reduced corneocyte cohesion, and reduced water-binding capacity of the stratum corneum are mechanisms of skin damage due to contact with detergents. washing hands. This study found a statistical test that was not significant between wet work and hand dermatitis because the appearance of dermatitis was influenced by the type of wet work and the duration of doing wet work.

\section{CONCLUSION}

Based on the analysis and discussion, it can be concluded that risk factors, wet work, atopic history, age, gender, years of service are not related to the incidence of hand dermatitis in hospital nurses in Sukoharjo.

\section{REFERENCES}

Agarwal, Uma Shankar, Besarwal, Raj Kumar, Gupta, Rahul, Agarwal, Puneet, \& Napalia, Sheetal. (2014). Hand eczema. Indian Journal of Dermatology, 59(3), 213.

Ale, Iris S., \& Maibach, Howard I. (2014). Irritant contact dermatitis. Reviews on Environmental Health, 29(3), 195-206.

Cristóbal, Lara, de Los Reyes, Nerea, Ortega, Miguel A., Álvarez-Mon, Melchor, García-Honduvilla, Natalio, Buján, Julia, \& Maldonado, Andrés A. (2019). Local growth hormone therapy for pressure ulcer healing on a human skin mouse model. International Journal of Molecular Sciences, 20(17), 4157.

Dąbrowska, A. K., Spano, Fabrizio, Derler, Siegfried, Adlhart, Christian, Spencer, Nicholas D., \& Rossi, René M. (2018). The relationship between skin function, barrier properties, and body-dependent factors. Skin Research and Technology, 24(2), 165-174.

Mortz, C. G., Bindslev-Jensen, C., \& Andersen, Klaus Ejner. (2014). Hand eczema in The $\mathrm{O}$ dense $\mathrm{A}$ dolescence $\mathrm{C}$ ohort $\mathrm{S}$ tudy on A topic $\mathrm{D}$ iseases and D ermatitis (TOACS): prevalence, incidence and risk factors from adolescence to adulthood. British Journal of Dermatology, 171(2), 313-323.

Rive, Craig M., Bourke, Jack, \& Phillips, Elizabeth J. (2013). Testing for drug hypersensitivity syndromes. The Clinical Biochemist Reviews, 34(1), 15.

Salvador, J. F. Silvestre, Mendaza, F. Heras, Garcés, M. Hervella, PalaciosMartínez, D., Camacho, R. Sánchez, Sanz, R. Senan, González, A. Apellaniz, \& Giménez-Arnau, A. M. (2020). Guidelines for the diagnosis, treatment, and prevention of hand eczema. Actas Dermo-Sifiliográficas (English Edition), 111(1), 26-40.

Santer, Miriam, Burgess, Hana, Yardley, Lucy, Ersser, Steven, Lewis-Jones, Sue, Muller, Ingrid, Hugh, Catherine, \& Little, Paul. (2012). Experiences of carers managing childhood eczema and their views on its treatment: a qualitative study. British Journal of General Practice, 62(597), e261-e267.

Sharmila Rao, V. (2018). Clinico-epidemiological and etiological study of hand eczema. Madras Medical College, Chennai. 
Tan, Cher Han, Rasool, Sarah, \& Johnston, Graham A. (2014). Contact dermatitis: allergic and irritant. Clinics in Dermatology, 32(1), 116-124.

Thomsen, Simon F. (2015). Epidemiology and natural history of atopic diseases. European Clinical Respiratory Journal, 2(1), 24642. 